\title{
A Novel Nomogram for Prediction of Early Postoperative Complications of Total Gastrectomy for Gastric Cancer
}

\author{
Jiawen Zhang* \\ Linhua Jiang* \\ Xinguo Zhu
}

Department of General Surgery, The First Affiliated Hospital of Soochow University, Suzhou, Jiangsu, People's Republic of China

*These authors contributed equally to this work
Correspondence: Xinguo Zhu

Department of General Surgery, The First Affiliated Hospital of Soochow University, Suzhou, 21 5006, Jiangsu, People's Republic of China

Email zhuxinguo2020@I63.com
Background: Accurate prediction of postoperative complications is especially important for the formulation of treatment plans for patients with total gastrectomy (TG) for gastric cancer (GC). The purpose of this study was to establish a risk assessment model for early postoperative complications.

Methods: This retrospective study involved 363 patients with GC who underwent TG from January 2019 to December 2020. The influencing factors were explored by univariate and multivariable logistic regression; then, a nomogram was established and verified by internal verification. Results: Linear stapler $(\mathrm{OR}=2.501, \mathrm{P}=0.030)$, age $(\mathrm{OR}=1.052, \mathrm{P}=0.024)$, blood transfusion (yes) $(\mathrm{OR}=2.450, \mathrm{P}=0.021)$, one-time consumables for surgery ( or $=1.000, \mathrm{P}=0.022)$, number of total lymph nodes $(\mathrm{OR}=1.060, \mathrm{P}=0.011)$ and number of positive lymph nodes $(\mathrm{OR}=1.054$, $\mathrm{P}=0.029$ ) were independent risk factors for early postoperative complications in TG, and nomogram model was constructed. The C-index of primary cohort, modeling cohort and validation cohort was $0.787,0.754$ and 0.912 . The calibration curves showed good accuracy.

Conclusion: This study used the indicators available before and during surgery to establish a nomogram model for early postoperative complications of total gastrectomy for gastric cancer, which found that linear stapler (LS), blood transfusion, one-time consumables for surgery, number of total lymph nodes and number of positive lymph nodes were factors.

Keywords: gastric cancer, total gastrectomy, early postoperative complications, prediction model, nomogram

\section{Introduction}

Gastric cancer (GC) is a major health issue worldwide, which remains the third leading cause of cancer death. ${ }^{1}$ With the gradual increase of tumors in the upper and middle stomach, research and evaluation of how to deal with such tumors came into view, which made the research on TG necessary, although gastric cancer in East Asia mostly occurred in the lower third of the stomach. ${ }^{2,3}$

TG is still a challenging operation in the surgical treatment of gastric cancer. This is not only because it needs to perform lymph node dissection under laparoscopy, but also because the reconstruction of the digestive tract needs to be completed. ${ }^{4-8}$ Complications adversely affect patients' health condition and is associated with high morbidity and mortality rates. ${ }^{9-12}$ The etiology of complications, especially the complications related to the anastomosis, is multifactorial and generally believed to be sex, age, surgical situation and the general condition of the patient. ${ }^{13}$ Careful management of postoperative complications in total gastrectomy is necessary. 
Due to the numerous related risk factors, the use of accurate predictive tools and early intervention may be the most effective preventive measures for complications. Currently, nomograms have been developed in the majority of cancer types. ${ }^{14,15}$ The application of Norman diagram not only plays an important role in the prognosis and survival of tumor patients, but also in the prediction of anastomoticrelated complications in other cancer. ${ }^{16}$ To our knowledge, this study is the first attempt to establish a prognostic nomogram for early postoperative complications after total gastrectomy, to determine whether to predict the occurrence of complications and timely intervention.

\section{Method}

\section{Study Patients}

We retrospectively collected all patients undergoing total gastrectomy with D2 lymphadenectomy during January 2019 to December 2020 in the First Affiliated Hospital of Soochow University, and finally after inclusion and exclusion, 363 patients were included in the final study. The process for patient selection is presented in Figure 1. All patients were operated under standard general anesthesia, follow the guidelines for surgical treatment and lymph node dissection. The study protocol was approved by the Ethics Committee of the First Affiliated Hospital of Soochow University. We confirm that our study complies with the Declaration of Helsinki. This project was conducted as a retrospective observational study, the study protocol involved minimal risk and did not threaten the health of the subjects. And, all participating patients signed informed consents.

\section{Inclusion and Exclusion Criteria}

The inclusion criteria of this study were as follows: ${ }^{1}$ patients who underwent total gastrectomy with D2 lymphadenectomy; ${ }^{2}$ no neoadjuvant radiotherapy or chemotherapy was used before surgery. Exclusion criteria were: ${ }^{1}$ incomplete clinical data and failed to regain ${ }^{2}$ preoperative examination or intraoperative detection of distant metastasis or invasion; ${ }^{3}$ combined organ resection, and $d^{4}$ palliative surgery.

\section{Definition of Complications}

Complications were defined as any deviation from the normal postoperative course. ${ }^{17}$ According to the Clavien-Dindo classification, postoperative complications were recorded within 30 days after surgery and those who were judged to be grade II and above were regarded as the observation indicators. ${ }^{18}$ Briefly, complications included nervous system complications, cardiac complications, pneumonia, ileus, anastomotic leakage, anastomotic stenosis, anastomotic bleeding, pancreatic fistula, abdominal abscess, incisional surgical site infection and hemorrhage. The diagnosis of complications is mainly through clinical symptoms and signs, CT, endoscopy, drainage fluid, and individual laboratory examinations.

\section{Data Collection}

Patient's baseline data were collected upon admission as following: Age, sex (male or female), body mass index (BMI), preoperative BMI, preoperative albumin, preoperative hemoglobin, ASA staging (I-VI), ECOG PS (0-5), presence of cardiopulmonary comorbidity (yes or no), diabetes, hypertension (yes or no) and renal impairment

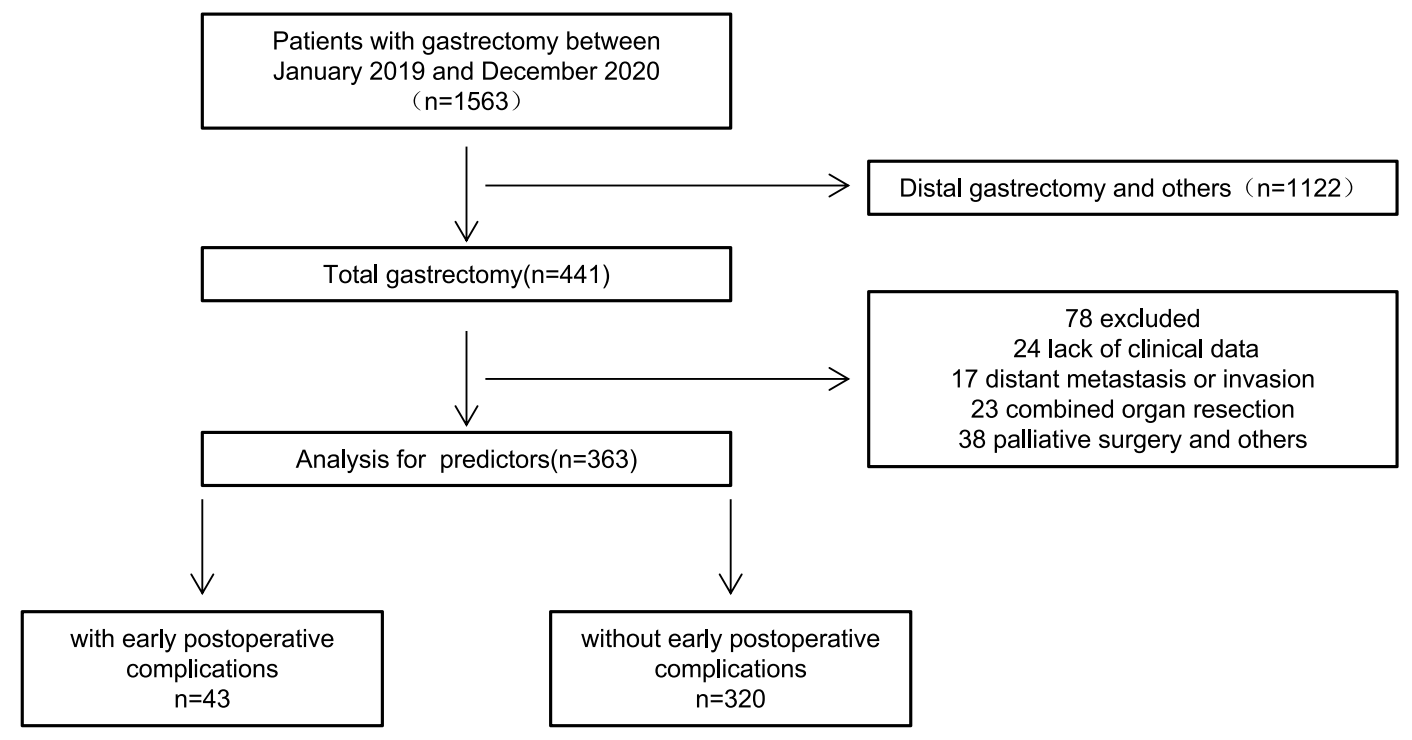

Figure I Flow of patients through this retrospective study. Ultimately, 363 patients were enrolled who underwent TG for GC. 
(yes or no). The operation time, blood transfusion (yes or no), jejunum feeding tube (yes or no), one-time consumables for surgery, total cost of hospitalization and hospital stay were also obtained. Simultaneously, in terms of tumors, tumor long diameter, tumor short diameter, $\mathrm{T}$ stage (T1-2 or T3-4), number of total lymph nodes, number of positive lymph nodes, vascular invasion (yes or no) and nerve invasion (yes or no) were collected. Over the study period, preoperative albumin and hemoglobin were extracted at the first admission. Tumor size was measured with combination of intraoperative conditions and postoperative pathology according to the long and short diameter of the tumor. Blood transfusion refers to whether there is blood transfusion during the period from the operation to the discharge from the hospital or the occurrence of postoperative complications.

\section{Propensity Score Matching}

Patients were categorized into two groups based on with or without early postoperative complications. Patients in groups were matched using the propensity score method. The propensity score for an individual was calculated using age, gender, BMI, tumor long diameter and tumor short diameter.

\section{Model Establishment and Validation}

Univariate and multivariable logistic regression models were used to detect the relationship between variables and complications. In the univariate analysis, crude analyses were performed to identify potential risk factors. All variables having a bivariate association with complications with $\mathrm{P}<0.1$ were included in the multivariable model. The results were displayed as odds ratios (ORs) and 95\% confidence intervals (CIs).

We used a random sampling method, according to $7: 3$ to select patients into the validation cohort, in order to complete the internal verification. We used the concordance index (C-index) to measure differences between performance and predicted results of the nomograms. ${ }^{19,20}$ Calibration curves were used to compare the predicted results of the nomogram with the actual results, while the 45-degree line was used as the optimal model. ${ }^{21}$

Continuous variables with normal distributions were presented as mean standard deviation and categorical variables were presented as number (percentage). All statistical analyses were performed using SPSS software (version 26.0) and R software (http://www.Rproject.org), and random sampling and model establishment were all accomplished by $\mathrm{R}$ software and $\mathrm{P}<0.05$ was considered to indicate a statistically significant difference.

\section{Results}

\section{A Propensity Score-Matched Clinical and Pathological Characteristics}

The flow of patients through this retrospective study is summarized in Figure 1, ultimately, 363 patients including 43 patients occurred early postoperative complications and 320 patients who survived were enrolled. The clinical and pathological characteristics of the 36 propensity scorematched patients are shown in Table 1, meanwhile Figures 2 and 3 show that after matching between the

Table I Comparison of Clinical and Pathological Data of the Patients

\begin{tabular}{|c|c|c|c|c|c|c|}
\hline \multirow[t]{2}{*}{ Variable } & \multicolumn{2}{|c|}{ All Patients $(n=363)$} & \multirow[b]{2}{*}{$\mathbf{P}$} & \multicolumn{2}{|c|}{ Patients After Matching $(n=72)$} & \multirow[b]{2}{*}{$\mathbf{P}$} \\
\hline & $\begin{array}{l}\text { With Early } \\
\text { Postoperative } \\
\text { Complications } \\
\quad(n=43)\end{array}$ & $\begin{array}{l}\text { Without Early } \\
\text { Postoperative } \\
\text { Complications } \\
\quad(n=320)\end{array}$ & & $\begin{array}{l}\text { With Early } \\
\text { Postoperative } \\
\text { Complications } \\
\quad(n=36)\end{array}$ & $\begin{array}{l}\text { Without Early } \\
\text { Postoperative } \\
\text { Complications } \\
\quad(n=36)\end{array}$ & \\
\hline Age (years) & 65.40 & 66.03 & 0.6944 & 66.64 & 69.08 & 0.1891 \\
\hline $\begin{array}{c}\text { Gender } \\
\text { Male } \\
\text { Female }\end{array}$ & $\begin{array}{l}30 \\
13\end{array}$ & $\begin{array}{c}238 \\
82\end{array}$ & 0.5187 & $\begin{array}{c}27 \\
9\end{array}$ & $\begin{array}{c}27 \\
9\end{array}$ & 0.9999 \\
\hline BMI & 22.58 & 22.98 & 0.4867 & 22.82 & 22.41 & 0.5616 \\
\hline Tumor long diameter & 4.733 & 5.140 & 0.3822 & 4.808 & 5.000 & 0.7573 \\
\hline Tumor short diameter & 3.453 & 3.810 & 0.3022 & 3.550 & 3.644 & 0.8422 \\
\hline
\end{tabular}

Abbreviation: BMI, body mass index. 


\section{Distribution of Propensity Scores}

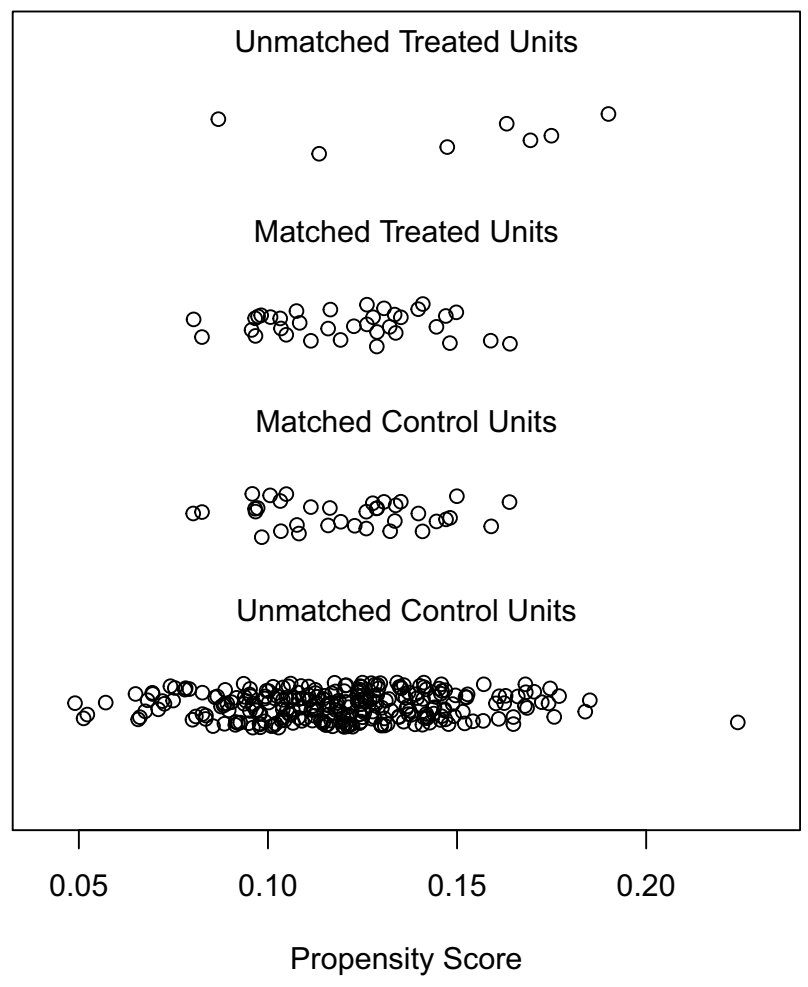

Figure 2 Distribution Figure: After matching between the two groups, the score distribution is consistent, and the matching effect is good.

two groups, the score distribution is consistent, and the matching effect is good. As determined by the study design, age, gender, BMI, Tumor long diameter and Tumor short diameter in with or without early postoperative complications were comparable. There were no significant group differences in age, gender, BMI, tumor long diameter and tumor short diameter.

The surgical and pathological outcomes in the propensity score-matched patients are shown in Table 2. There is no statistical difference in ASA staging, ECOG, cardiopulmonary comorbidity, diabetes, hypertension and renal impairment both before and after PSM. The preoperative albumin was lower in patients who occurred early postoperative complications (36.39 vs 39.38, $\mathrm{P}=0.0099$ ). Furthermore it shows significant group differences in stapler and $\mathrm{T}$ stage after propensity score matching $(\mathrm{P}<0.05)$. There were no significant group differences in other factors.

The clinicopathological factors of patients who enrolled included a total of 363 patients and 108 training data obtained through random sampling by using $\mathrm{R}$ software which showed in Table 3. And there is no statistical difference in the data between the two cohorts, which also reflects the good randomization effect. Among all patients the number of patients with complications was $43(11.8 \%)$ and among training cohort the number was $11(10.1 \%)$.

\section{Sifted Independent Risk Factors and Development of the Nomogram Model}

Before constructing the nomogram model, clinicopathological features were evaluated using univariate and multivariate analysis. Univariate analysis found that the factors associated with complications in TG were LS $(\mathrm{OR}=3.547,95 \% \quad \mathrm{CI}=1.810-6.950, \quad \mathrm{P}=0.000), \quad$ age $(\mathrm{OR}=1.068,95 \% \mathrm{CI}=1.026-1.113, \mathrm{P}=0.001)$, blood transfusion (yes) $(\mathrm{OR}=2.967,95 \% \quad \mathrm{CI}=1.547-5.748, \mathrm{P}=0.000)$, one-time consumables for surgery $(\mathrm{OR}=1.000,95 \%$ $\mathrm{CI}=1.000-1.001, \mathrm{p}=0.001$ ), number of total lymph nodes $(\mathrm{OR}=1.091,95 \% \mathrm{CI}=1.052-1.132, \mathrm{P}=0.001)$ and number of positive lymph nodes $(\mathrm{OR}=1.101,95 \% \quad \mathrm{CI}=1.060$ 1.114, $\mathrm{P}=0.001)$. Multivariate analysis showed that the independent risk factors for complications in $\mathrm{TG}$ were LS $\quad(\mathrm{OR}=2.501,95 \% \quad \mathrm{CI}=1.095-5.716, \quad \mathrm{P}=0.030)$, age $(\mathrm{OR}=1.052,95 \% \mathrm{CI}=1.007-1.098, \mathrm{P}=0.024)$, blood transfusion (yes) $(\mathrm{OR}=2.450,95 \% \mathrm{CI}=1.147-5.234, \mathrm{P}=0.021)$, one-time consumables for surgery $(\mathrm{OR}=1.000,95 \%$ $\mathrm{CI}=1.000-1.001, \mathrm{p}=0.022$ ), number of total lymph nodes $(\mathrm{OR}=1.060,95 \% \mathrm{CI}=1.014-1.109, \mathrm{P}=0.011)$ and number of positive lymph nodes $(\mathrm{OR}=1.054,95 \% \quad \mathrm{CI}=1.005-$ $1.104, \mathrm{P}=0.029$ ) (Table 4). Other factors are not statistically significant risk factors.

Based on the aforementioned results, we established a nomogram model. By projecting the points corresponding to each variable to the "Points" axis, calculating the total scores gives the corresponding prediction results. ${ }^{21}$

\section{Performance Assessment and Validation of the Nomogram}

A nomogram model was successfully established (Figure 4) using the multivariate logistic regression results. The discrimination was appraised by $\mathrm{C}$-index. The C-index correctly predicted the probability of positive events in a survival prediction model through a group of randomly selected patients. ${ }^{10}$ In the primary cohort, the C-index of the nomogram was 0.787 . At the same time, the $\mathrm{C}$-index in modeling cohort and validation cohort were 0.754 and 0.912. -figure 7 show the calibration curves of primary cohort, modeling cohort and validation cohort; the model demonstrated good consistency. 
Raw Treated

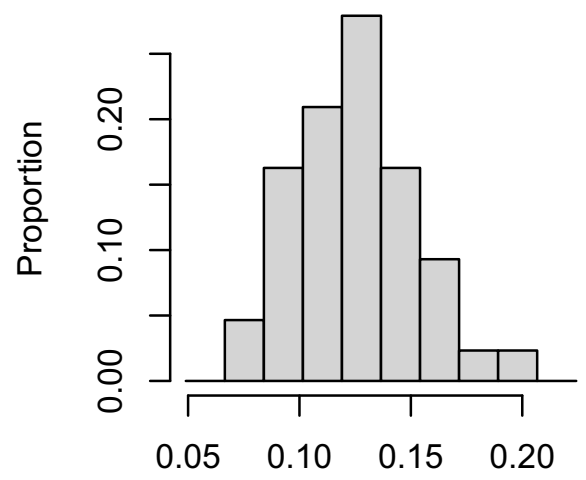

Propensity Score

Raw Control

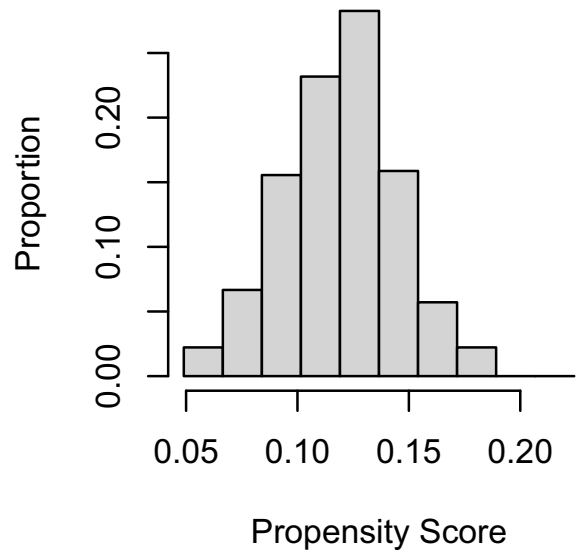

Matched Treated

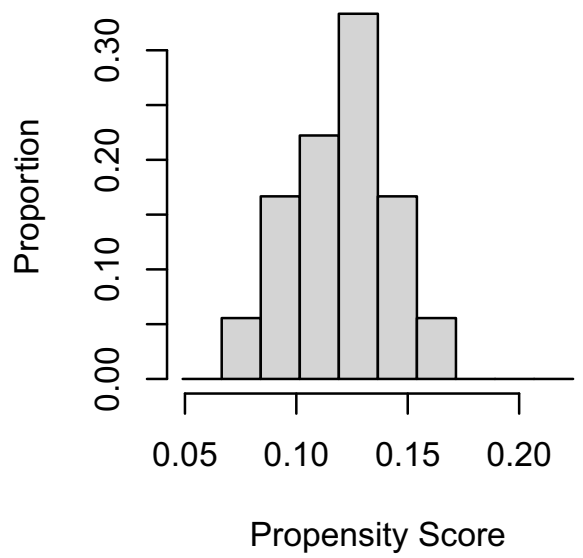

Matched Control

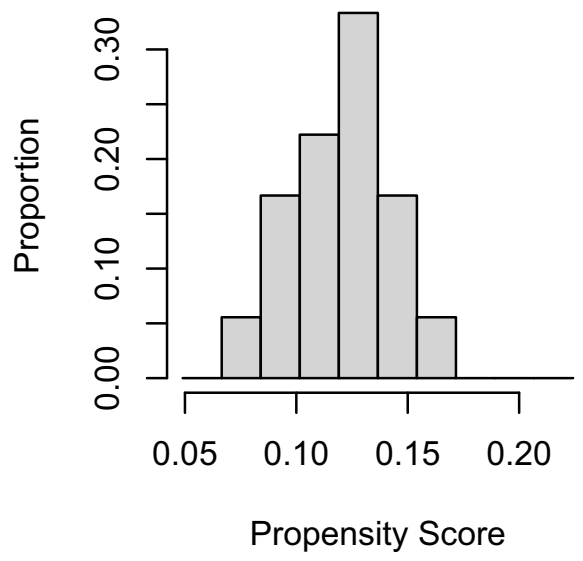

Figure 3 Histogram Figure: After matching between the two groups, the score distribution is consistent, and the matching effect is good.

\section{Discussion}

This study analyzed 16 potential variables of early postoperative complications in $363 \mathrm{GC}$ patients who underwent total gastrectomy. The following independent risk factors were identified: LS, age, blood transfusion, onetime consumables for surgery, number of total lymph nodes and number of positive lymph nodes. A simple and easy-to-use prediction nomogram for early postoperative complications after total gastrectomy using multivariate analyses was developed for the first time. Six variables were filtered out for the nomogram using stepwise regression. This nomogram had a good diagnostic performance (C-index $=0.787)$ and was validated internally using the random sampling method. Besides, the calibration curves demonstrates good consistency.
There are some reports on the risk factors of patients with complications following digestive surgery. ${ }^{22,23}$ Studies believe that many factors such as advanced age, open surgery, advanced tumor staging, postoperative analgesia, smoking history, diabetes, the presence of arrhythmia may be risk factors for complications after digestive surgery including gastric cancer, esophageal cancer and rectal cancer. In the study of esophageal cancer, anastomotic leakage is one of the most serious complications after esophageal cancer surgery because it affects prognosis and increases mortality. One study was conducted in 2012 by Noble et al, who combined postoperative laboratory indicators, including postoperative CRP levels, white cell counts and albumin levels, as predictors of $\mathrm{AL}$ and major complications. At the same 
Table 2 Surgical and Pathological Outcome of the Patients

\begin{tabular}{|c|c|c|c|c|c|c|}
\hline \multirow[t]{2}{*}{ Variable } & \multicolumn{2}{|c|}{ All Patients $(n=363)$} & \multirow[b]{2}{*}{$\mathbf{P}$} & \multicolumn{2}{|c|}{ Patients After Matching ( $n=72)$} & \multirow[b]{2}{*}{$\mathbf{P}$} \\
\hline & $\begin{array}{c}\text { With Early } \\
\text { Postoperative } \\
\text { Complications } \\
(n=43)\end{array}$ & $\begin{array}{c}\text { Without Early } \\
\text { Postoperative } \\
\text { Complications } \\
(n=320)\end{array}$ & & $\begin{array}{c}\text { With Early } \\
\text { Postoperative } \\
\text { Complications } \\
(n=36)\end{array}$ & $\begin{array}{c}\text { Without Early } \\
\text { Postoperative } \\
\text { Complications } \\
\quad(n=36)\end{array}$ & \\
\hline Preoperative albumin & 36.54 & 37.34 & 0.3316 & 36.39 & 39.38 & 0.0099 \\
\hline Preoperative hemoglobin & 117.0 & 118.3 & 0.7469 & 113.8 & 121.9 & 0.1586 \\
\hline Hypertension & & & $0.314 \mid$ & & & 0.6236 \\
\hline Yes & 18 & 109 & & 14 & 12 & \\
\hline No & 25 & 211 & & 22 & 24 & \\
\hline Diabetes & & & 0.7837 & & & 0.4533 \\
\hline Yes & 5 & 42 & & 3 & 5 & \\
\hline No & 38 & 278 & & 33 & 31 & \\
\hline Cardiopulmonary & & & 0.0829 & & & 0.4533 \\
\hline Yes & 6 & 21 & & 5 & 3 & \\
\hline No & 37 & 299 & & 31 & 33 & \\
\hline Renal impairment & & & 0.2443 & & & 0.5215 \\
\hline Yes & 2 & 6 & & 2 & 1 & \\
\hline No & 41 & 314 & & 34 & 35 & \\
\hline ASA staging & & & 0.0897 & & & 0.7807 \\
\hline I & 20 & 170 & & 22 & 20 & \\
\hline II & 17 & 133 & & 10 & 10 & \\
\hline III & 6 & 17 & & 4 & 6 & \\
\hline IV & 0 & 0 & & 0 & 0 & \\
\hline v & 0 & 0 & & 0 & 0 & \\
\hline $\mathrm{VI}$ & 0 & 0 & & 0 & 0 & \\
\hline ECOG & & & 0.9784 & & & 0.7050 \\
\hline 0 & 30 & 223 & & 25 & 28 & \\
\hline 1 & 12 & 91 & & 10 & 7 & \\
\hline 2 & 1 & 6 & & 1 & 1 & \\
\hline 3 & 0 & 0 & & 0 & 0 & \\
\hline 4 & 0 & 0 & & 0 & 0 & \\
\hline 5 & 0 & 0 & & 0 & 0 & \\
\hline Stapler & & & 0.0686 & & & 0.0090 \\
\hline LS & 13 & 59 & & 12 & 3 & \\
\hline CS & 30 & 261 & & 24 & 33 & \\
\hline Blood transfusion & & & 0.9978 & & & 0.1336 \\
\hline Yes & 16 & 119 & & 15 & 9 & \\
\hline No & 27 & 201 & & 21 & 27 & \\
\hline Jejunal feeding tube & & & 0.4286 & & & 0.7814 \\
\hline Yes & 9 & 85 & & 8 & 9 & \\
\hline No & 34 & 235 & & 28 & 27 & \\
\hline Operation time & 224.9 & 229.3 & 0.7155 & 223.4 & 220.7 & 0.8506 \\
\hline Vascular invasion & & & 0.3335 & & & 0.2296 \\
\hline Yes & 13 & 121 & & 12 & 17 & \\
\hline No & 30 & 199 & & 24 & 19 & \\
\hline
\end{tabular}

(Continued) 
Table 2 (Continued).

\begin{tabular}{|c|c|c|c|c|c|c|}
\hline \multirow[t]{2}{*}{ Variable } & \multicolumn{2}{|c|}{ All Patients $(n=363)$} & \multirow[b]{2}{*}{$\mathbf{P}$} & \multicolumn{2}{|c|}{ Patients After Matching $(n=72)$} & \multirow[b]{2}{*}{$\mathbf{P}$} \\
\hline & $\begin{array}{l}\text { With Early } \\
\text { Postoperative } \\
\text { Complications } \\
\quad(n=43)\end{array}$ & $\begin{array}{l}\text { Without Early } \\
\text { Postoperative } \\
\text { Complications } \\
\quad(n=320)\end{array}$ & & $\begin{array}{l}\text { With Early } \\
\text { Postoperative } \\
\text { Complications } \\
\quad(n=36)\end{array}$ & $\begin{array}{l}\text { Without Early } \\
\text { Postoperative } \\
\text { Complications } \\
\qquad(n=36)\end{array}$ & \\
\hline Nerve invasion & & & 0.6974 & & & 0.8119 \\
\hline Yes & 18 & 144 & & 16 & 15 & \\
\hline No & 25 & 176 & & 20 & 21 & \\
\hline T stage & & & 0.0007 & & & 0.0422 \\
\hline $1-2$ & 14 & 41 & & 11 & 4 & \\
\hline $3-4$ & 29 & 279 & & 25 & 32 & \\
\hline Number of total lymph nodes & 21.12 & 22.15 & 0.3961 & 20.14 & 21.25 & 0.4330 \\
\hline Number of positive lymph nodes & 4.093 & 5.565 & 0.1832 & 4.250 & 5.944 & 0.2628 \\
\hline One-time consumables for surgery & 30,513 & 29,948 & 0.7489 & 30,436 & 29,796 & 0.7548 \\
\hline Total cost of hospitalization & 68,594 & 67,504 & 0.7442 & 69,870 & 66,942 & 0.4817 \\
\hline Hospital stay & 15.42 & 15.75 & 0.6922 & 15.47 & 15.50 & 0.9813 \\
\hline
\end{tabular}

Abbreviations: LS, liner stapler; CS, circle stapler; ASA staging, American Society of Anesthesiology staging; ECOG, Eastern Cooperative Oncology Group performance status.

time, there are studies that focus on the preoperative and intraoperative conditions, focusing on the preoperative nutritional status, underlying diseases, and the patient's intraoperative anastomotic method, anastomotic position, and intraoperative hemorrhage. ${ }^{24}$ Postoperative complications of rectal cancer are also believed to cause mortality and increase the rate of permanent stoma formation. Studies have shown that high BMI, tumor size, distance from the anus, vascular ligation, blood transfusion, and stapler may all be related to complications. ${ }^{25-27}$

Gastric cancer is a common malignant tumor of the digestive tract, and radical resection is the most effective treatment for patients. ${ }^{1}$ Early postoperative complications will affect the patient's postoperative recovery, discharge time, and total cost. Through the study of early postoperative complications, it is conducive to early detection of the occurrence of complications in patients, and is conducive to early adoption of necessary measures.

Previous studies have mainly focused on postoperative laboratory biomarker data, which is quite different from our study. The main advantage of the current study is that our nomogram is easier and more intuitive than existing methods, and our nomogram includes different parameters to consider preoperative, intraoperative and pathological related factors.

There is no consensus on the comparison of circular and linear stapler in the surgical safety of total gastrectomy and the patient's postoperative recovery. The meta-analysis suggests that the linear stapler is less likely to have anastomotic complications in the reconstruction of the digestive tract after gastric cancer surgery. ${ }^{28}$ The patients included in this study were all patients undergoing total gastrectomy, without distal gastrectomy and other surgical methods. The reasons for the more likely early postoperative complications after the linear stapler may include: 1 . Usually more esophagus needs to be separated; 2 . The linear stapler is more used in the case of total laparoscopic anastomosis, which makes the anastomosis more difficult than open surgery; 3 . The reinforcement of the anastomosis is often not modeled; 4. Possibility of positive margins. However, the linear stapler still has some advantages compared with the circular stapler, such as a larger anastomosis, which reduces the occurrence of emptying obstacles, and has a lower requirement for trocar. ${ }^{28,29}$

In previous studies, it was uncertain whether age was a risk factor for anastomotic leakage. ${ }^{30}$ Studies believe that as the age increases, the likelihood of postoperative complications will increase, especially if the age is older than $65 .^{31}$ This is the same as the results of our study. The increase in patient age is an independent risk factor for early postoperative complications. This may be because patients tend to have worse nutritional status at an advanced age and have more underlying diseases. For example, vascular disease may affect the blood supply of the patient's esophagojejunostomy, distal anastomosis and incision, 
Table 3 Demographic or Characteristic Date of the Patient in Primary Cohort and Validation Cohort

\begin{tabular}{|c|c|c|}
\hline Demographic or Characteristic & $\begin{array}{c}\text { Primary } \\
\text { Cohort } \\
N=363\end{array}$ & $\begin{array}{c}\text { Validation } \\
\text { Cohort } \mathrm{N}=108\end{array}$ \\
\hline Age & 66.02 & 65.36 \\
\hline \multicolumn{3}{|l|}{ Gender } \\
\hline Male & 268 & 76 \\
\hline Female & 95 & 32 \\
\hline Preoperative BMI & 22.88 & 22.61 \\
\hline Preoperative albumin & 37.25 & 36.87 \\
\hline Preoperative hemoglobin & 118.2 & 117.8 \\
\hline \multicolumn{3}{|l|}{ Hypertension } \\
\hline Yes & 127 & 37 \\
\hline No & 236 & 71 \\
\hline \multicolumn{3}{|l|}{ Diabetes } \\
\hline Yes & 47 & 16 \\
\hline No & 316 & 92 \\
\hline \multicolumn{3}{|l|}{ Cardiopulmonary } \\
\hline Yes & 27 & 9 \\
\hline No & 336 & 99 \\
\hline \multicolumn{3}{|l|}{ Renal impairment } \\
\hline Yes & 8 & 3 \\
\hline No & 355 & 105 \\
\hline \multicolumn{3}{|l|}{ ASA staging } \\
\hline 1 & 190 & 56 \\
\hline$\|$ & 150 & 47 \\
\hline III & 23 & 5 \\
\hline IV & 0 & 0 \\
\hline v & 0 & 0 \\
\hline VI & 0 & 0 \\
\hline \multicolumn{3}{|l|}{ ECGO } \\
\hline 0 & 253 & 78 \\
\hline 1 & 103 & 28 \\
\hline 2 & 7 & 2 \\
\hline 3 & 0 & 0 \\
\hline 4 & 0 & 0 \\
\hline 5 & 0 & 0 \\
\hline \multicolumn{3}{|l|}{ Stapler } \\
\hline LS & 72 & 20 \\
\hline CS & 291 & 88 \\
\hline \multicolumn{3}{|l|}{ Blood transfusion } \\
\hline Yes & 135 & 65 \\
\hline No & 228 & 43 \\
\hline \multicolumn{3}{|l|}{ Jejunal feeding tube } \\
\hline Yes & 94 & 78 \\
\hline No & 269 & 30 \\
\hline Operation time & 228.7 & 220.8 \\
\hline
\end{tabular}

(Continued)
Table 3 (Continued).

\begin{tabular}{|l|c|c|}
\hline Demographic or Characteristic & $\begin{array}{c}\text { Primary } \\
\text { Cohort } \\
\text { N=363 }\end{array}$ & $\begin{array}{c}\text { Validation } \\
\text { Cohort N=108 }\end{array}$ \\
\hline Tumor long diameter & 5.091 & 4.901 \\
\hline Tumor short diameter & 3.767 & 3.707 \\
\hline $\begin{array}{l}\text { Vascular invasion } \\
\text { Yes }\end{array}$ & 134 & 36 \\
No & 229 & 72 \\
\hline Nerve invasion & 162 & 48 \\
Yes & 201 & 60 \\
\hline No & 55 & 14 \\
\hline stage & 308 & 94 \\
\hline I-2 & 22.15 & 22.41 \\
\hline Number of total lymph nodes & 5.603 & 5.750 \\
\hline Number of positive lymph nodes & 30,384 & 31,593 \\
\hline One-time consumables for surgery & 67,754 & 68,040 \\
\hline Total cost of hospitalization & 15.71 & 15.35 \\
\hline Hospital stay & 320 & 11 \\
\hline Complication & & 97 \\
\hline Yes & 53 & \\
\hline
\end{tabular}

Abbreviations: BMI, body mass index; LS, liner stapler; CS, circle stapler; ASA staging, American Society of Anesthesiology staging; ECOG, Eastern Cooperative Oncology Group performance status.

making the incidence of anastomosis-related complications higher. ${ }^{32}$ And in our clinical experience, elderly patients tend to have poor compliance, which will make the patient's recovery slower, make the fluid intake time and the time to get out of bed later, and make the risk of intestinal obstruction and thrombosis higher.

A significant proportion of patients require blood transfusion during the perioperative period of gastrointestinal surgery. ${ }^{33}$ Studies have shown that blood transfusion is a risk factor affecting the prognosis of patients regardless of whether it is in surgery for gastric cancer or colorectal cancer. ${ }^{34-36}$ Part of patients with gastric cancer are usually in a long-term anemia state before surgery, which is related to the reduction of food intake and chronic consumption of the tumor. Meanwhile, during the operation, due to the abundant blood supply of the stomach and the removal of lymph nodes, intraoperative bleeding is inevitable There is increasing evidence that blood transfusion is related to postoperative systemic inflammatory response in 
Table 4 Univariate and Multivariable Analysis of Factors Influencing Early Postoperative Complications of Total Gastrectomy for Gastric Cancer

\begin{tabular}{|l|c|c|c|c|}
\hline \multirow{2}{*}{ Factors } & \multicolumn{2}{|c|}{ Univariate Analysis } & \multicolumn{2}{c|}{ Multivariate Analysis } \\
\cline { 2 - 5 } & OR (95\% CI) & P & I \\
\hline $\begin{array}{c}\text { Stapler } \\
\text { CS } \\
\text { LS }\end{array}$ & 1 & 0.000 & 0.030 \\
\hline Age & $3.547(1.810,6.950)$ & $2.501(1.095,5.716)$ & 0.024 \\
\hline $\begin{array}{l}\text { Blood transfusion } \\
\text { No } \\
\text { Yes }\end{array}$ & $1.068(1.026,1.113)$ & 0.001 & $1.052(1.007,1.098)$ & 0.021 \\
\hline One-time consumables for surgery & $1.000(1.000,1.001)$ & 0.000 & 1 & $0.050(1.147,5.234)$ \\
\hline Number of total lymph nodes & $1.091(1.052,1.132)$ & 0.001 & $1.000(1.000,1.001)$ & 0.011 \\
\hline Number of positive lymph nodes & $1.101(1.060,1.114)$ & 0.001 & $1.060(1.014,1.109)$ & 0.029 \\
\hline
\end{tabular}

Abbreviations: LS, liner stapler; CS, circle stapler.

patients, which in turn is related to postoperative complications of patients. In this study, blood transfusion will make patients more likely to have early postoperative complications. ${ }^{37-39}$ Moreover, the choice of blood transfusion is considered to be related to the difficulty of the operation, the amount of blood loss, the basic condition before the operation, and the stage of the tumor. ${ }^{36,40}$

One-time consumables for surgery includes the cost of intraoperative monitoring, anesthesia consumables, surgical consumables (including staplers, hemostatic materials, etc.),

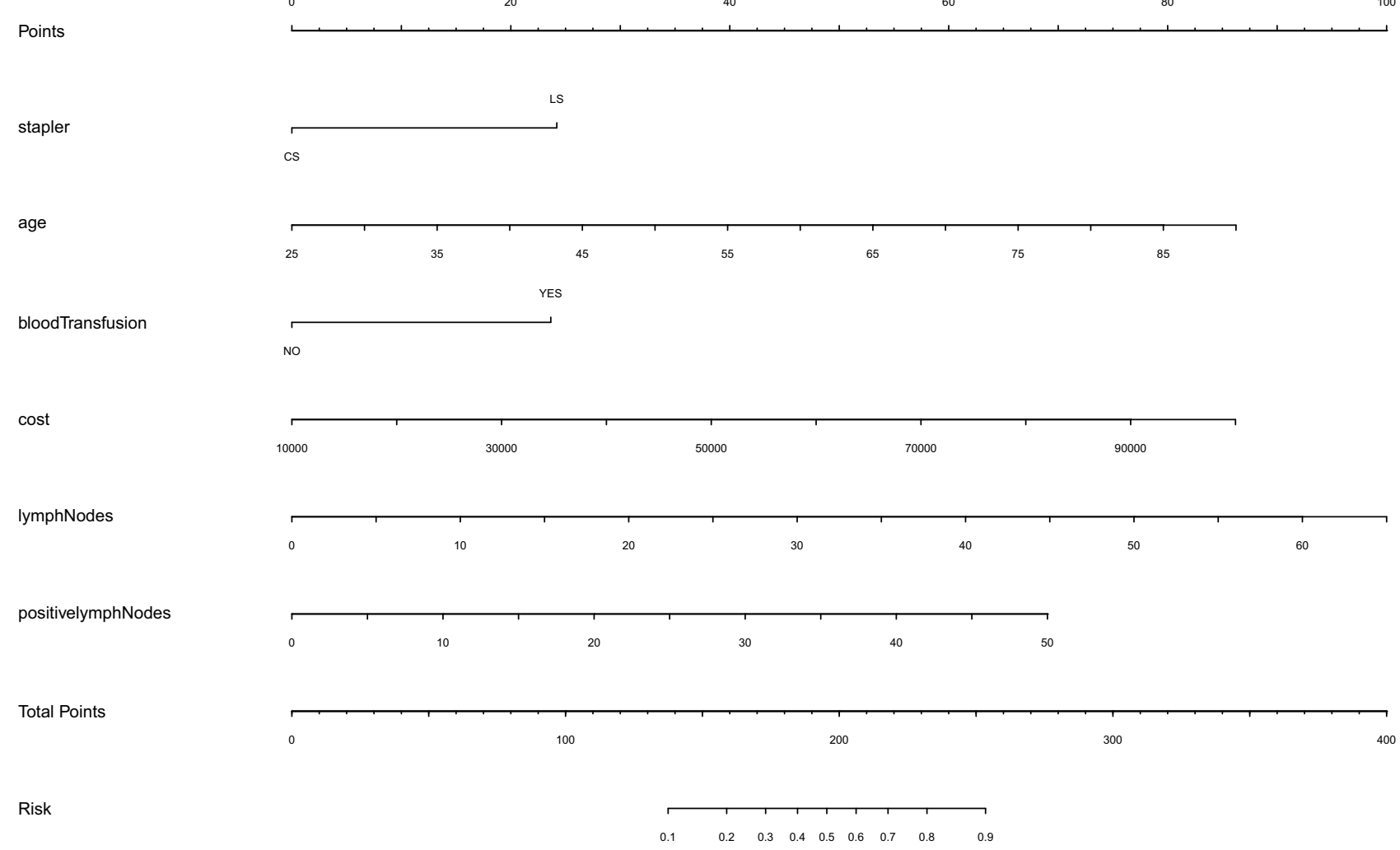

Figure 4 The nomogram for predicting the risk of early postoperative complications of total gastrectomy for gastric cancer. Cost, one-time consumables for surgery. LymphNodes, number of total lymph nodes. PositivelymphNodes, number of positive lymph nodes. 


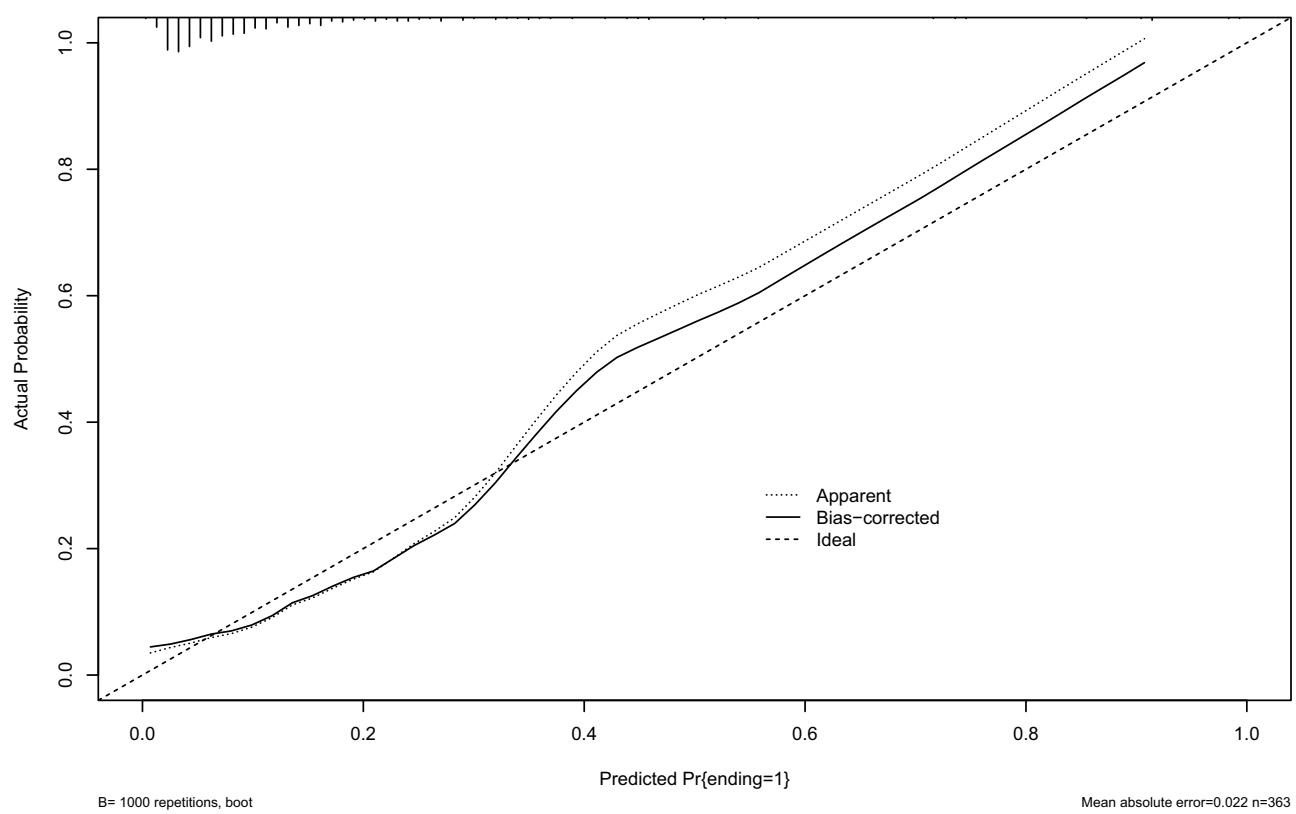

Figure 5 Calibration plots of primary cohort.

Notes: The $y$-axis is the actual rate. The $x$-axis is the predicted risk. The diagonal dotted line represents a perfect prediction by an ideal model. The solid line represents the bias-corrected performance of the nomogram, where a closer fit to the diagonal dotted line represents a better prediction.

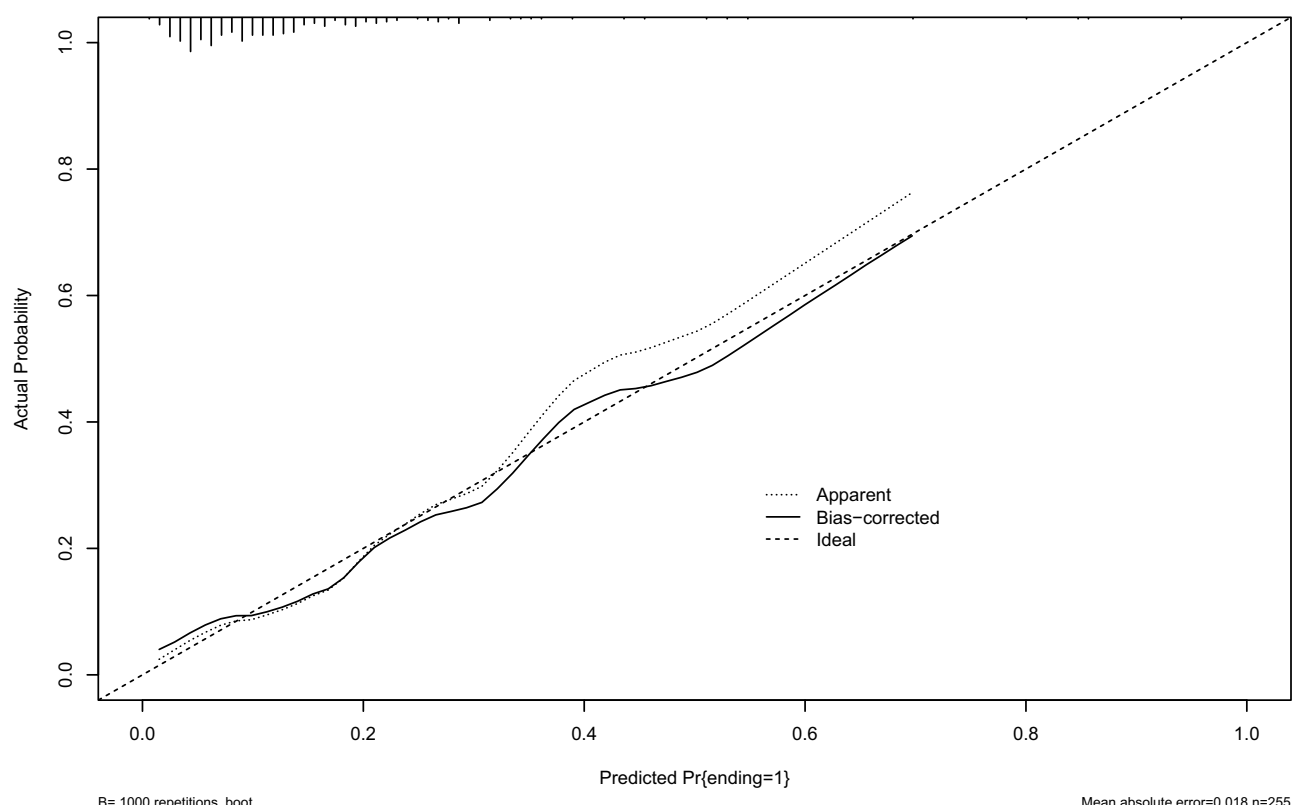

Figure 6 Calibration plots of modeling cohort.

and the cost of other items used in the operation. Longer operation time, more stapler use, and more surgical bleeding may cause a significant increase in intraoperative costs. Precise prediction and calculation of surgical costs can reduce the incidence of complications and reduce costs. ${ }^{41,42}$

In this study, it was found that the total number of lymph nodes dissected and positive lymph nodes may be risk factors for early postoperative complications, but they are not statistically significant with the $\mathrm{T}$ stage and tumor size of the tumor. More advanced tumors often indicate a worse prognosis. Patients with the same stage often have a significantly different prognosis, indicating that Patient recovery and prognosis is a multi-factor and complex process, and it is difficult to predict only by a single staging system. 


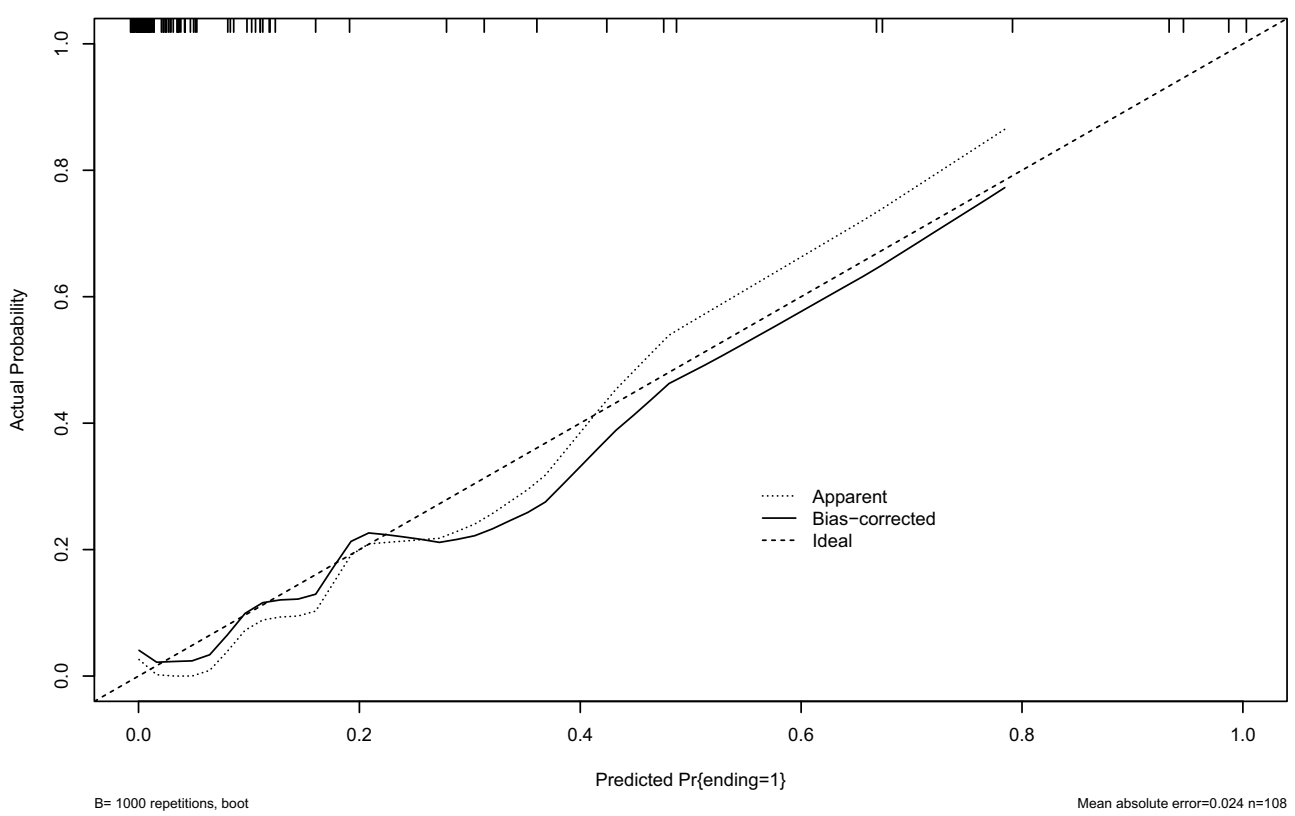

Figure 7 Calibration plots of validation cohort.

The present study comprehensively analyzed the prognostic factors of early postoperative complications after total gastrectomy and established an accurate and convenient nomogram prognostic model, which carried internal verification to evaluate the performance of the model accurately. However, there were still some shortcomings. First of all, this study is a retrospective study, inevitably there are some unknown factors leading to bias. In addition, information about the survival of patients after surgery was not taken into consideration in the study. The main reason was that the postoperative time of the included patients was short, and the follow-up study will continue. In addition, in order to more accurately evaluate the performance of the model, external verification based on other centers is also required. However, the current results are still encouraging. This predictive model has a certain guiding role in the detection of early complications after surgery. More patients and predictive factors are worthy of being included.

In this study, we used the indicators available before and during surgery to establish a nomogram model for early postoperative complications of total gastrectomy for gastric cancer and found that LS, blood transfusion, one-time consumables for surgery, number of total lymph nodes and number of positive lymph nodes were independent risk factors. And verified the model through internal verification methods, which proved that the model has good consistency.

\section{Disclosure}

Jiawen Zhang, Linhua Jiang, Xinguo Zhu have no conflicts of interest or financial ties to disclose.

\section{References}

1. Bray F, Ferlay J, Soerjomataram I, Siegel RL, Torre LA, Jemal A. Global cancer statistics 2018: GLOBOCAN estimates of incidence and mortality worldwide for 36 cancers in 185 countries. CA Cancer J Clin. 2018;68(6):394-424. doi:10.3322/caac.21492

2. Jeong O, Park YK. Clinicopathological features and surgical treatment of gastric cancer in South Korea: the results of 2009 nationwide survey on surgically treated gastric cancer patients. $J$ Gastric Cancer. 2011;11 (2):69-77. doi:10.5230/jgc.2011.11.2.69

3. Kitano S, Shiraishi N. Current status of laparoscopic gastrectomy for cancer in Japan. Surg Endosc. 2004;18(2):182-185. doi:10.1007/ s00464-003-8820-7

4. Bracale U, Marzano E, Nastro P, et al. Side-to-side esophagojejunostomy during totally laparoscopic total gastrectomy for malignant disease: a multicenter study. Surg Endosc. 2010;24(10):2475-2479. doi:10.1007/s00464-010-0988-z

5. Okabe H, Obama K, Tsunoda S, Tanaka E, Sakai Y. Advantage of completely laparoscopic gastrectomy with linear stapled reconstruction: a long-term follow-up study. Ann Surg. 2014;259(1):109-116. doi:10.1097/SLA.0b013e31828dfa5d

6. Inaba K, Satoh S, Ishida Y, et al. Overlap method: novel intracorporeal esophagojejunostomy after laparoscopic total gastrectomy. J Am Coll Surg. 2010;211(6):e25-9. doi:10.1016/j. jamcollsurg.2010.09.005

7. Du J, Shuang J, Li J, Li J, Hua J. Intracorporeal circular-stapled esophagojejunostomy after laparoscopic total gastrectomy: a novel self-pulling and holding purse-string suture technique. $J$ Am Coll Surg. 2014;218(3):e67-72. doi:10.1016/j.jamcollsurg.2013.11.023

8. Ebihara Y, Okushiba S, Kawarada Y, Kitashiro S, Katoh H. Outcome of functional end-to-end esophagojejunostomy in totally laparoscopic total gastrectomy. Langenbecks Arch Surg. 2013;398(3):475-479. doi:10.1007/s00423-013-1051-z 
9. Kim MJ, Shin R, Oh HK, Park JW, Jeong SY, Park JG. The impact of heavy smoking on anastomotic leakage and stricture after low anterior resection in rectal cancer patients. World J Surg. 2011;35 (12):2806-2810. doi:10.1007/s00268-011-1286-1

10. Choi DH, Hwang JK, Ko YT, et al. Risk factors for anastomotic leakage after laparoscopic rectal resection. J Korean Soc Coloproctol. 2010;26(4):265-273. doi:10.3393/jksc.2010.26.4.265

11. Liu Y, Wan X, Wang G, et al. A scoring system to predict the risk of anastomotic leakage after anterior resection for rectal cancer. $J$ Surg Oncol. 2014;109(2):122-125. doi:10.1002/jso.23467

12. Jatal S, Pai VD, Demenezes J, Desouza A, Saklani AP. Analysis of risk factors and management of anastomotic leakage after rectal cancer surgery: an Indian series. Indian J Surg Oncol. 2016;7 (1):37-43. doi:10.1007/s13193-015-0457-1

13. Messager M, Warlaumont M, Renaud F, et al. Recent improvements in the management of esophageal anastomotic leak after surgery for cancer. Eur J Surg Oncol. 2017;43(2):258-269. doi:10.1016/j. ejso.2016.06.394

14. Bochner BH, Kattan MW, Vora KC; International Bladder Cancer Nomogram C. Postoperative nomogram predicting risk of recurrence after radical cystectomy for bladder cancer. J Clin Oncol. 2006;24 (24):3967-3972.

15. Karakiewicz PI, Briganti A, Chun FK, et al. Multi-institutional validation of a new renal cancer-specific survival nomogram. $J$ Clin Oncol. 2007;25(11):1316-1322. doi:10.1200/JCO.2006.06.1218

16. Wang L, Hricak H, Kattan MW, Chen HN, Scardino PT, Kuroiwa K. Prediction of organ-confined prostate cancer: incremental value of MR imaging and MR spectroscopic imaging to staging nomograms. Radiology. 2006;238(2):597-603. doi:10.1148/radiol.2382041905

17. Clavien PA, Sanabria JR, Strasberg SM. Proposed classification of complications of surgery with examples of utility in cholecystectomy. Surgery. 1992;111(5):518-526.

18. Dindo D, Demartines N, Clavien PA. Classification of surgical complications: a new proposal with evaluation in a cohort of 6336 patients and results of a survey. Ann Surg. 2004;240(2):205-213. doi:10.1097/01.sla.0000133083.54934.ae

19. Koziol JA, Jia Z. The concordance index $C$ and the Mann-Whitney parameter $\operatorname{Pr}(\mathrm{X}>\mathrm{Y})$ with randomly censored data. Biom J. 2009;51 (3):467-474. doi:10.1002/bimj.200800228

20. Brentnall AR, Cuzick J. Use of the concordance index for predictors of censored survival data. Stat Methods Med Res. 2018;27 (8):2359-2373. doi:10.1177/0962280216680245

21. Iasonos A, Schrag D, Raj GV, Panageas KS. How to build and interpret a nomogram for cancer prognosis. J Clin Oncol. 2008;26 (8):1364-1370. doi:10.1200/JCO.2007.12.9791

22. Tsujinaka S, Konishi F, Kawamura YJ, et al. Visceral obesity predicts surgical outcomes after laparoscopic colectomy for sigmoid colon cancer. Dis Colon Rectum. 2008;51(12):1757-65; discussion 65-7. doi:10.1007/s10350-008-9395-0

23. Seki Y, Ohue M, Sekimoto M, et al. Evaluation of the technical difficulty performing laparoscopic resection of a rectosigmoid carcinoma: visceral fat reflects technical difficulty more accurately than body mass index. Surg Endosc. 2007;21(6):929-934. doi:10.1007/ s00464-006-9084-9

24. Huang C, Yao H, Huang Q, Lu H, Xu M, Wu J. A novel nomogram to predict the risk of anastomotic leakage in patients after oesophagectomy. BMC Surg. 2020;20(1):64. doi:10.1186/s12893020-00726-7

25. Yang L, Huang XE, Zhou JN. Risk assessment on anastomotic leakage after rectal cancer surgery: an analysis of 753 patients. Asian Pac J Cancer Prev. 2013;14(7):4447-4453. doi:10.7314/ APJCP.2013.14.7.4447

26. Komen N, Dijk JW, Lalmahomed Z, et al. After-hours colorectal surgery: a risk factor for anastomotic leakage. Int $J$ Colorectal Dis. 2009;24(7):789-795. doi:10.1007/s00384-009-0692-4
27. Shiwakoti E, Song J, Li J, Wu S, Zhang Z. Prediction model for anastomotic leakage after laparoscopic rectal cancer resection. $J$ Int Med Res. 2020;48(9):300060520957547.

28. Umemura A, Koeda K, Sasaki A, et al. Totally laparoscopic total gastrectomy for gastric cancer: literature review and comparison of the procedure of esophagojejunostomy. Asian J Surg. 2015;38 (2):102-112. doi:10.1016/j.asjsur.2014.09.006

29. Schneider R, Gass JM, Kern B, et al. Linear compared to circular stapler anastomosis in laparoscopic Roux-en-Y gastric bypass leads to comparable weight loss with fewer complications: a matched pair study. Langenbecks Arch Surg. 2016;401(3):307-313. doi:10.1007/ s00423-016-1397-0

30. Huang J, Zhou Y, Wang C, et al. Logistic regression analysis of the risk factors of anastomotic fistula after radical resection of esophageal-cardiac cancer. Thorac Cancer. 2017;8(6):666-671. doi:10.1111/1759-7714.12509

31. Sun ZW, Du H, Li JR, Qin HY. Constructing a risk prediction model for anastomotic leakage after esophageal cancer resection. $J$ Int Med Res. 2020;48(4):300060519896726.

32. Fjederholt KT, Okholm C, Svendsen LB, Achiam MP, Kirkegard J, Mortensen FV. Ketorolac and other NSAIDs increase the risk of anastomotic leakage after surgery for GEJ cancers: a cohort study of 557 patients. J Gastrointest Surg. 2018;22(4):587-594. doi:10.1007/s11605-017-3623-7

33. Acheson AG, Brookes MJ, Spahn DR. Effects of allogeneic red blood cell transfusions on clinical outcomes in patients undergoing colorectal cancer surgery: a systematic review and meta-analysis. Ann Surg. 2012;256(2):235-244. doi:10.1097/SLA.0b013e31825b35d5

34. Squires MH 3rd, Kooby DA, Poultsides GA, et al. Effect of perioperative transfusion on recurrence and survival after gastric Cancer resection: a 7-institution analysis of 765 patients from the US gastric cancer collaborative. $J$ Am Coll Surg. 2015;221(3):767-777. doi:10.1016/j.jamcollsurg.2015.06.012

35. Mizuno A, Kanda M, Kobayashi D, et al. Adverse effects of intraoperative blood loss on long-term outcomes after curative gastrectomy of patients with stage II/III gastric cancer. Dig Surg. 2016;33 (2):121-128. doi:10.1159/000443219

36. McSorley ST, Tham A, Dolan RD, et al. Perioperative blood transfusion is associated with postoperative systemic inflammatory response and poorer outcomes following surgery for colorectal cancer. Ann Surg Oncol. 2020;27(3):833-843. doi:10.1245/s10434-019-07984-7

37. Blumberg N, Heal JM. Effects of transfusion on immune function. Cancer recurrence and infection. Arch Pathol Lab Med. 1994;118 (4):371-379.

38. Vamvakas EC, Blajchman MA. Transfusion-related immunomodulation (TRIM): an update. Blood Rev. 2007;21(6):327-348. doi:10.1016/j.blre.2007.07.003

39. Watt DG, McSorley ST, Park JH, Horgan PG, McMillan DC. A postoperative systemic inflammation score predicts short- and long-term outcomes in patients undergoing surgery for colorectal cancer. Ann Surg Oncol. 2017;24(4):1100-1109. doi:10.1245/ s10434-016-5659-4

40. Xu D, Fang X, Li Y, Zhang Z, Li Q. Perioperative blood transfusion is one of the factors that affect the prognosis of gastric cancer. J BUON. 2018;23(3):672-677.

41. Eamer GJ, Clement F, Holroyd-Leduc J, Wagg A, Padwal R, Khadaroo RG. Frailty predicts increased costs in emergent general surgery patients: a prospective cohort cost analysis. Surgery. 2019;166(1):82-87. doi:10.1016/j.surg.2019.01.033

42. De la Plaza Llamas R, Ramia JM. Cost of postoperative complications: how to avoid calculation errors. World $J$ Gastroenterol. 2020;26(21):2682-2690. doi:10.3748/wjg.v26.i21.2682 


\section{Publish your work in this journal}

Cancer Management and Research is an international, peer-reviewed open access journal focusing on cancer research and the optimal use of preventative and integrated treatment interventions to achieve improved outcomes, enhanced survival and quality of life for the cancer patient.
The manuscript management system is completely online and includes a very quick and fair peer-review system, which is all easy to use. Visit http://www.dovepress.com/testimonials.php to read real quotes from published authors.

Submit your manuscript here: https://www.dovepress.com/cancer-management-and-research-journal 